\title{
O ENSINO COMO TRABALHO: REFLEXÕES SOBRE A DIMENSÃO PRESCRITIVA DO ENSINO DE ANÁLISE LINGUÍSTICA EM DOCUMENTOS OFICIAIS
}

\author{
Teaching as work: reflections on the prescriptive dimension of \\ teaching in linguistic analysis in official documents
}

Francisco Rafael Mota de SOUSA Programa de Pós-Graduação em Linguística Aplicada

Universidade Estadual de Campinas rafael.motta@hotmail.com https://orcid.org/0000-0002-0791-4652

Mônica de Souza SERAFIM

Universidade Federal do Ceará mserafim15@gmail.com https://orcid.org/0000-0003-1518-3009

Pollyanne Bicalho RIBEIRO Universidade Federal do Ceará pollyanne.bicalho@gmail.com https://orcid.org/0000-0002-5128-8089

RESUMO: Compreender a disciplina Língua Portuguesa requer não só dominar os conhecimentos de tal campo, mas mobilizá-los com outros aspectos da prática educativa, incluindo as recomendações de documentos oficiais. Entendidos como textos que prescrevem o trabalho docente, esses documentos constituem política oficial de Estado, direcionando a práxis pedagógica de modo a atingir os objetivos propostos. Assim, este artigo reflete sobre a dimensão prescritiva do componente curricular Língua Portuguesa no Ensino Fundamental Anos Finais a partir da discussão sobre como os documentos oficiais recomendam o ensino de Análise Linguística. Para isso, fundamentados no conceito de trabalho prescrito (CLOT, 2007, 2013; MACHADO, 2002) e nas discussões sobre ensino de gramática/análise linguística (GERALDI, 2004; MENDONÇA, 2006), analisamos os Parâmetros Curriculares Nacionais (PCN) e a Base Nacional Comum Curricular (BNCC), considerando as concepções de língua/linguagem e os objetivos para o ensino de Análise Linguística. Um confronto dos dois documentos mostrou que, por serem guiados por uma perspectiva sociointeracionista da linguagem,

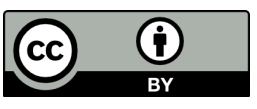


confluem em muitos pontos sobre o ensino de Análise Linguística a partir de uma vertente que toma a língua em função de seus usos sociais. Tal perspectiva reivindica uma configuração do ensino de português alicerçado numa visão dialógica de linguagem, cujas práticas didáticas devem contribuir para a ampliação dos letramentos dos estudantes. PALAVRAS-CHAVE: Ensino de Análise Linguística; Trabalho prescrito; Documentos oficiais; Dialogismo.

\begin{abstract}
Understanding the discipline Portuguese Language requires not only mastering the knowledge of such a field, but mobilizing them with other aspects of educational practice, including recommendations from official documents. Being understood as texts that prescribe teaching work, these documents are official State policies, directing pedagogical praxis in order to achieve the proposed objectives. Thus, this article reflects on the prescriptive dimension of the curricular component Portuguese Language in Elementary Education Final Years from the discussion on how the official documents recommend the teaching of Linguistic Analysis. For this, based on the concept of prescribed work (CLOT, 2007, 2013; MACHADO, 2002) and on discussions about teaching grammar/linguistic analysis (GERALDI, 2004; MENDONÇA, 2006), we analyzed the National Curriculum Parameters and the Common National Curricular Base, considering the conceptions of language and the objectives for the teaching of Linguistic Analysis. A comparison of the two documents showed that, being guided by a sociointeractionist perspective of language, they converge in many points on the teaching of Linguistic Analysis from a perspective that takes the language in function of its social uses. This perspective demands a configuration of Portuguese teaching based on a dialogical view of language, whose didactic practices should contribute to the expansion of students' literacies. KEYWORDS: Linguistic analysis teaching; Prescribed work; Official documents; Dialogism.
\end{abstract}

\title{
INTRODUÇÃO
}

A compreensão da gramática como uma disciplina escolar (SANTOS, 1990), ou seja, como um saber ensinado pela/na escola, implica que se tome como reflexão não só os conhecimentos que esse próprio campo mobiliza, como também exige que se abarquem os diferentes processos educacionais. Defender esse posicionamento é aceitar a ideia de que práticas pedagógicas no ensino e na aprendizagem de língua materna sempre são incorporadas por concepções de linguagem, de escola, de sujeito aluno, de trabalho docente, de comunidade etc. Tais concepções, em conjunto com diferentes 
processos que também cercam o ambiente e o cotidiano escolar, constituem a própria escola e caracterizam o aspecto político inevitavelmente inerente da prática educativa.

Podemos considerar que os processos didáticos passam ou se revestem, necessariamente, de uma posição política, confirmando a tênue relação entre a escola, que reflete os ideais sociais, e a sociedade, que os impõe. Importante destacar também que tal posicionamento se constitui não somente de concepções - que, no ensino de Língua Portuguesa, podem ser a noção de língua/linguagem, de gramática, de educação linguística, de escola etc. - , mas também dos próprios procedimentos que refletem tais juízos. Dito de outra maneira, não há prática sem concepção, nem há escola sem uma política que a envolva.

Dentro dessa perspectiva, é importante que conheçamos os diferentes processos que orbitam o ambiente escolar, de modo que possamos ter a possibilidade de compreender o espaço da escola em todas as suas dimensões, sejam elas política, social, histórica, cultural e, em nosso caso, linguística. Esse caráter pluridimensional das práticas pedagógicas advém mesmo da concepção de escola como sendo uma instituição aberta às transformações pelas quais a sociedade passa, aliada a mecanismos que propõem/impõem essa prática escolar plural. É assim que podemos, como bem sustenta Geraldi (2004), buscar entender como a escola escolhe o que ensina, como ensina, quando ensina etc.

Essa busca não ocorre à toa, mas é sempre influenciada por escolhas que, inclusive, refletem-se na própria nomenclatura do que se denomina de ensino de gramática e que, desde os anos 80, trata de ser renomeada por ensino de Análise de Linguística (GERALDI, 2004 [1984]). Essencialmente, essa nomenclatura vem mostrar que a prática de análise linguística não se limita à higienização do texto do aluno em seus aspectos gramaticais e ortográficos, mas que se precisa trabalhar com o aluno o seu texto para que ele atinja seus objetivos junto aos leitores a que se destina. Dessa forma, a proposta de Geraldi (2004 [1984]) não exclui um trabalho com situações sistemáticas da língua, mas o amplia, considerando aspectos relacionados ao contexto de interação.

Dentre os mecanismos que buscam criar condições para a escola exercer seu aspecto plural, estão os chamados documentos oficiais. Entendidos aqui como um conjunto de textos que regulam as ações da escola (MACHADO, 2002), esses documentos constituem em sua essência uma política linguística oficial de Estado e atuam como autênticos "enunciados que configuram diálogos/conflitos interculturais e políticas de letramento no sistema educacional público brasileiro" (TORQUATO, 2016, p. 428). Isso significa que, do ponto de vista político, tais textos configuram parte essencial da prática 
educativa, pois direcionam o trabalho que deve ser realizado pelos mais diversos atores do ambiente escolar.

Assim, uma compreensão dos modos de como o ensino de Gramática/Análise Linguística configurou-se na escola passa necessariamente, também, pela análise e reflexão do que os documentos oficiais (trabalho prescrito) dispõem a respeito do ensino dos conhecimentos linguísticos. Seguindo tal perspectiva, este artigo discute a dimensão prescritiva do ensino de Gramática/Análise Linguística a partir do confronto de dois documentos oficiais brasileiros que tratam do ensino de língua materna: os Parâmetros Curriculares Nacionais, publicados em 1997, e a Base Nacional Comum Curricular, promulgada em 2018, verificando como esses documentos oficiais recomendam a prática escolar desse aspecto da língua. Antes, porém, cumpre tecermos algumas reflexões no sentido de compreender como tais documentos se configuram como trabalho de prescrição a respeito do ensino de línguas, o que requer evocarmos algumas considerações da Ergonomia da Atividade e da Clínica da Atividade, ciências que hoje se debruçam a estudar a organização do trabalho e, de modo particular, suas relações com a linguagem.

\section{OS DOCUMENTOS OFICIAIS COMO TRABALHO PRESCRITO}

Reflexões mais sistematizadas sobre a organização do trabalho humano datam do século XVI, estima Bronckart (2008), durante o desenvolvimento do capitalismo na Europa, que culminou com a Revolução Industrial. Apresentando uma definição que, no decorrer do tempo, sofreu uma série de transformações, o trabalho - entendido pelo autor como uma instituição social (BRONCKART, 2008) — pode ser caracterizado hoje como uma atividade própria do homem, atuando como um impulsionador de seu desenvolvimento social e humano. Devido às contínuas e rápidas transformações pelas quais o termo passou, em virtude de configurações novas nas relações sociais entre o homem e a sua prática de trabalho, diversas linhas teóricas de estudo sobre o trabalho começaram a emergir com o intuito de entender como tal instituição funciona e quais seus impactos na sociedade.

Destaca-se, no campo das ciências humanas e sociais, uma disciplina que enfoca "as novas dimensões do trabalho e seus problemas" (BARIONI, 2016, p. 53): a Ergonomia, que passou cada vez mais a buscar, dentre outras preocupações, uma compreensão das práticas de trabalho marcadas pela linguagem (BARIONI, 2016). No interior dessa relação entre trabalho e linguagem, duas tendências se sobressaem: a Ergonomia da Atividade, que busca melhorar o bem-estar do trabalhador, e a Clínica da Atividade, com sua preocupação mais direcionada para os aspectos subjetivos, em que se Revista X, v. 16, n. 3, p. 798-821, 2021. 
busca, através da ação, melhorar a qualidade de vida dos trabalhadores. Recentemente, no campo das investigações linguísticas, tanto a Ergonomia da Atividade quanto a Clínica da Atividade buscam compreender três tipos de relações estabelecidas entre o trabalho e a linguagem (BARIONI, 2016):

a. Linguagem como trabalho - consistindo no uso da linguagem para realizar uma determinada atividade de trabalho;

b. Linguagem no trabalho - caracterizando o uso da linguagem em situação de uma atividade de trabalho;

c. Linguagem sobre o trabalho - correspondendo às diferentes produções de saber sobre a atividade de trabalho.

Ainda segundo a autora, a Clínica da Atividade, constituindo uma vertente teórico-metodológica da Ergonomia da Atividade de linha francesa, tem como propósito compreender e promover a construção saudável de pessoas a partir da intervenção direta em seu ambiente de trabalho. Isso porque, como bem pontua Clot (2013), a qualidade do trabalho interfere também na qualidade de vida do indivíduo, o que pressupõe que não só a dimensão do trabalho a ser feito e do trabalho já realizado é importante, mas também a função psicológica (CLOT, 2007) que envolve essas duas outras dimensões. Nesse sentido, para o autor, a atividade do trabalho não é um exercício simples, pois seu esforço é um indicador de saúde (CLOT, 2013).

Diante das inevitáveis crises que acometem milhares de trabalhadores ao redor do mundo, a partir das quais se desenvolvem diferentes tipos de doenças, problemas emocionais e sentimentos de despreparo, Clot (2013, p. 25) afirma que é necessário reconhecer, de forma legítima, "a existência de conflitos sobre a qualidade do trabalho e, ao invés de negar esses conflitos, institucionalizá-los" para que os trabalhadores possam ter a possibilidade de usufruir novamente daquilo que o autor chama de "poder de agir", isto é, o poder de investimento de esforços que o trabalhador desenvolve para com o seu objeto de trabalho. Ainda segundo o autor, quando a qualidade do trabalho é afetada, o trabalhador está sendo privado de seu poder de agir e, então, a qualidade de vida do trabalhador é seriamente afetada.

Clot (2007), nesse sentido, defende a ideia de que não é o trabalhador que não está conseguindo atender às exigências de suas instituições de trabalho, mas sim essas instituições que não estariam atendendo às necessidades de seus trabalhadores. Para ele, o trabalho é uma atividade sempre em conflito que é dirigida a três polos: ao 
objeto, ao próprio sujeito e a outrem. Tal atividade, prossegue ele, sempre é mediada por instrumentos sócio-historicamente criados pelo coletivo, sejam eles materiais ou simbólicos e que, por sua vez, apresentam um conjunto de regras - que ele denomina "gêneros de atividade" — que interferem no agir do profissional.

Numa perspectiva que toma a linguagem como uma forma de agir (BRONCKART, 2008), pode-se confirmar que a linguagem, enquanto instrumento simbólico, guarda intrínsecas relações com a atividade do trabalho. Nesse cenário, o trabalho do professor e, no nosso caso, o trabalho do professor de língua materna, tem recebido as contribuições várias das ciências do trabalho no sentido não só de buscar respostas que ajudem a entender as relações de seu ofício no ambiente educacional através de uma análise de seus discursos (BRONKART, MACHADO, MATENCIO, 2006), mas principalmente buscar as relações entre o chamado "trabalho prescrito" e o "trabalho realizado" e seus impactos na atividade docente.

Por "trabalho prescrito", define Clot (2007), entende-se tudo aquilo que é orientado, ordenado ao professor e/ou aquilo que o professor prescreve para si mesmo. Em suma, refere-se a um conjunto de regras constituídas para orientar ou direcionar a ação do professor em sua atividade de trabalho. Para Machado e Bronckart (2005), o trabalho prescrito é homogeneizado pela escola, sendo delineado a partir dos textos prescritivos, que "incidem sobre a organização das classes, a distribuição do tempo disponível, os objetivos do ensino, as rotinas da interação, as ações a serem desenvolvidas etc.” (MACHADO; BRONCKART, 2005, p. 187). É a partir da prescrição que a ação do professor em situação de trabalho pode ser transformada, constituindo aí o chamado "trabalho realizado".

Amigues (2009), considerando a prescrição do trabalho um artefato cultural, destaca seu caráter histórico e sua sujeição às transformações no tempo e no espaço. $O$ autor pontua:

A prescrição é fruto do trabalho de "grupos de especialistas", "comitês de programas", é a manifestação de uma escolha política em um determinado momento da história de um país. O artefato prescritivo, parte de uma tradição cultural, nunca cessa de acumular e renovar as modificações feitas por um grupo social, uma dada sociedade. Petrificado por compromissos históricos, carrega memória, experiências acumuladas, sejam bem-sucedidas ou não. A prescrição geralmente se apresenta como nova e enraizada na tradição. Testemunho histórico de um processo social, é o resultado - atual e provisório - de sucessivas reformas (AMIGUES, 2009, p. 16). 
Diante do caráter sócio-histórico ao qual está inerentemente relacionado, o trabalho prescrito, como linguagem sobre o trabalho (BARIONI, 2016), torna-se uma memória ativa que, ao mesmo tempo em que traz consigo um conjunto de elementos que caracteriza os princípios, as ideias e os valores de uma determinada comunidade, também carrega o que não se pode atingir na atividade do trabalho. Nesse sentido, a prescrição, por si só, cria um diálogo entre este nível da atividade e o nível do trabalho realizado, já que tem o poder de reconfigurar suas ações.

Buscando caracterizar os "gêneros de atividade" que compõem o trabalho prescrito, Machado e Bronckart (2005) assinalam a dificuldade de se delimitar e classificar tais gêneros aos quais pertencem os textos prescritivos. Citando fundamentos teóricos da linguística textual de Jean-Michel Adam, os autores trazem propriedades genéricas desses textos, que se caracterizam essencialmente por serem produzidos por pessoas ditas "especialistas" em um determinado campo, que não aparecem explicitamente nos textos; por mencionarem os agentes das ações que prescreve; e por serem regidos por uma espécie de contrato que garante a verdade e a promessa de sucesso dada ao destinatário, caso este aja de acordo com as recomendações. Em linhas gerais, ainda segundo os autores, os textos prescritivos apresentam considerável e conhecido valor ilocutório, cujo estatuto hierárquico representa um dever para, dentro da ação do professor, mobilizar o agir dos alunos.

Dentro dessa perspectiva, Amigues (2009) considera que a prescrição pode ser vista como uma organizadora da atividade coletiva dos profissionais da educação, uma vez que tais textos selam "compromissos que o professor deve passar consigo mesmo (e com os outros) para aumentar não só 'a eficácia', mas também 'a eficiência' de sua ação" (AMIGUES, 2009, p. 15). Porém, como bem assinala Barioni (2016), esse compromisso estabelecido nunca ocorre sem conflitos, uma vez que nenhum trabalhador aplica as prescrições que lhe são impostas. Na verdade, destaca a autora, essa "obediência" à prescrição acontece nos processos de ajustes e adaptações que o próprio docente, nas suas práticas pedagógicas, conduz na tentativa conciliar a sua situação de trabalho com os objetivos a alcançar. Assim, conclui a autora que "para compreender o trabalho do professor, é necessário observar as tarefas que ele deve desempenhar, determinadas pelo que é orientado [...] e que são reelaboradas pelos professores nos diferentes contextos" (BARIONI, 2016, p. 59).

Diante das considerações acima, podemos reconhecer que os Parâmetros Curriculares Nacionais, bem como a Base Nacional Comum Curricular, por trazerem orientações precisas e de caráter prescritivo para o desenvolvimento do ensino de 
língua materna no Brasil, podem ser considerados documentos prescritivos e, portanto, direcionadores da atividade pedagógica. Além de se constituírem como artefatos simbólicos, para usar os termos de Clot (2007), esses materiais, tomados por si e para si pelo trabalhador, atuam como guias coletivos da atividade profissional de todos os que compõem a escola, interferindo diretamente sobre o fazer educacional. Pensados com essa única missão, tanto um como outro configuram seus textos e determinam seus objetos (sobre os quais a prescrição incide) de forma a, como bem pontua Clot (2007), resolver conflitos da atividade e, assim, constituir uma fonte fundamental para o chamado "trabalho bem-feito".

Para compreendermos melhor o funcionamento desses dois instrumentos simbólicos (iguais em sua essência, mas diferentes em seus métodos), discutimos a seguir os seus textos, tomando como base o que eles prescrevem a respeito do ensino de Gramática/Análise Linguística nas aulas de língua materna.

\section{OS PARÂMETROS CURRICULARES NACIONAIS E O ENSINO DE ANÁLISE LINGUÍSTICA}

Nas últimas décadas do século $\mathrm{XX}$, em razão do avanço do neoliberalismo no plano econômico e de governos ditatoriais, os períodos de redemocratização das nações que compõem a América Latina foram acompanhados de grande instabilidade financeira. Tal fato acabou por exigir, por sua vez, a construção de projetos de reformas políticas e programas de estabilização econômica como estratégia de salvaguardar a independência política e financeira dessas nações. No interior desse conjunto de reformas, destacouse em grande medida uma profunda revisão das filosofias e políticas educacionais que, agora apoiadas numa visão mais neoliberal, exigem uma qualidade e produtividade dos processos educativos a partir de uma série de estratégias.

No caso do Brasil, os Parâmetros Curriculares Nacionais (PCN, doravante) são um exemplo dessa preocupação. Para Suassuna (1998), porém, fora o fator econômico, outras ações e fenômenos no campo da educação interferiram na produção do documento, como a "aprovação da Lei de Diretrizes e Bases da Educação Nacional (LDB), reforma do ensino médio e profissionalizante, repasse direto de verbas às escolas, investimentos em equipamentos de educação a distância, avaliação de cursos superiores etc." (SUASSUNA, 1998, p. 177). Nesse sentido, o nascimento dos PCN seguiu muito mais uma linha que atendia aos interesses políticos e econômicos do que mesmo os próprios interesses da escola e suas reais necessidades. 
A elaboração de parâmetros para a construção de currículos educacionais está diretamente amparada pelas novas necessidades sócio-históricas que, no caso brasileiro - e pode-se dizer do mundo como um todo - estão assentadas nos princípios políticos e econômicos do capitalismo neoliberal, surgido nos fins do século XX. Nesse sentido, os PCN são vistos como um instrumento que busca possibilitar, às entidades governamentais e a outros segmentos da elite, os caminhos para que tais objetivos sejam atingidos em sua plenitude. Em outras palavras, os PCN estão a serviço do Estado que os impõe, e não da própria escola.

Nunes (2007), ao discutir ainda o caráter político do documento, no qual ocorre uma ideia de "adequação às necessidades culturais e políticas", defende essa pluralidade que os PCN buscam evocar. A autora explica que:

Esses parâmetros, por um lado, assegurariam uma aproximação da produção de conhecimento em todo o território nacional, por outro lado, permitiria uma adequação às necessidades culturais e políticas das diferentes regiões do país, o que permitiria a elaboração de currículos plurais, originados, também, da pluralidade das vocações regionais. Portanto, na intenção com que os PCNEFs foram produzidos, numa visão centrado/descentrada, ele permitiria uma transposição didática dos princípios referenciais do documento para as práticas educativas, assegurando uma unidade nacional, que sustentaria uma base nacional comum, ao lado das diversidades regionais (NUNES, 2007, p. 82-83).

Como se pode depreender das palavras da autora, os PCN funcionariam a partir da conjunção de duas frentes: a primeira, de caráter mais centralizado, referirse-ia à inclusão, por parte do documento, de um conjunto de orientações teóricas que fundamentariam a construção dos currículos escolares, garantindo-lhe unidade em todo o país; a segunda frente, de caráter mais descentralizado, estaria mais direcionado à realidade local das escolas, construindo um sistema de ensino e aprendizagem fundado na relação plural entre o nacional e o regional desse documento. Dessa forma, os PCN são documentos normativo-prescritivos, mas que, dentro dessa prescrição, existe, pelo menos em tese, a abertura para a flexibilização de outros saberes, atitudes, valores etc. Eis, na opinião ainda da autora, um aspecto diferenciador e inovador do documento. 
Com efeito, justificada pela obrigatoriedade de cumprir o artigo 210 da Constituição Federal de 1988, ratificado pela LDB de 1996', a elaboração dos PCN, segundo nos informam Rojo (2000) e Ferrarezi Jr. (2014), tornou-se um marco na história do currículo e, no nosso caso, da educação em língua materna no Brasil, pois trouxe reflexões sistematizadas e alinhadas com o que havia de mais recente na história dos estudos linguísticos realizados no país.

Diante dessas considerações expostas sobre os PCN de modo geral, partimos a seguir para uma descrição do documento referente ao volume de língua portuguesa, direcionado pelos seguintes aspectos: concepção de língua/linguagem, objetivos e estrutura de ensino de língua materna, conceito de texto e lugar destinado ao ensino da gramática/análise linguística. Esperamos, dessa forma, conseguir caracterizar o complexo arranjo teórico-metodológico do documento, de modo que possamos compreender o papel dos conhecimentos gramaticais no conjunto geral da obra em função dos aportes teóricos que o sustentam.

Os PCN dedicados ao ensino de língua portuguesa têm como espinha dorsal a ideia de que é necessário que a instituição escolar organize seu ensino em função do desenvolvimento dos "conhecimentos discursivos e linguísticos" (BRASIL, 1998, p. 59), conforme relaciona o volume introdutório do documento, que explica:

Em outras palavras, [os PCN de língua portuguesa] propõem que a escola organize o ensino de modo que o aluno possa desenvolver seus conhecimentos discursivos e linguísticos, sabendo: ler e escrever conforme seus propósitos e demandas sociais; expressar-se apropriadamente em situações de interação oral diferentes daquelas próprias de seu universo imediato; [e] refletir sobre os fenômenos da linguagem, particularmente os que tocam a questão da variedade linguística, combatendo a estigmatização, discriminação e preconceitos relativos ao uso da língua (BRASIL, 1998, p. 59).

A partir desse excerto, depreende-se que o ensino de língua portuguesa deve conduzir o aluno a desenvolver competências e habilidades para a sua vivência nas relações sociais. Esse objetivo almejado pode se efetivar a partir da prática de atividades de leitura e de produção de vários textos (escritos e orais), além de possibilitar, através

\footnotetext{
${ }^{1}$ Assim está disposto na LDB/1996: “Art. $9^{\circ}$ A União incumbir-se-á de: [...] IV - estabelecer, em colaboração com os Estados, o Distrito Federal e os Municípios, competências e diretrizes para a educação infantil, o ensino fundamental e o ensino médio, que nortearão os currículos e seus conteúdos mínimos, de modo a assegurar formação básica comum" (BRASIL, 1996, ênfase nossa). 
dessas atividades, que o aluno reflita sobre esses processos linguísticos de modo que ele perceba que, através da linguagem, ele pode atuar socialmente

Numa perspectiva claramente teórica, os postulados dos PCN alinham-se de forma considerável com o que se concebia a respeito das relações existentes entre língua e sociedade, na qual, seguindo os fundamentos do pensador russo Mikhail Bakhtin (1895-1975), a língua só se torna viva e real em situações de interação entre os membros situados sócio-historicamente de uma determinada sociedade. Nesse sentido, a linguagem em todas as suas manifestações é um meio para que os sujeitos ajam em diferentes espaços sociais, constituindo esses mesmos espaços e se constituindo enquanto sujeito histórico a partir da linguagem. Em outras palavras, falar, ouvir, ler e escrever são formas de agir na sociedade.

É nesse sentido que o conceito de linguagem nos PCN é importante, pois é nesta concepção que todos os objetivos de ensino, sua metodologia e suas práticas estarão assentadas. $\mathrm{O}$ volume dedicado à disciplina de língua portuguesa, por sua vez, considera inicialmente o conceito de língua/linguagem que vai direcionar toda a discussão teórico-pedagógica: “a linguagem é uma forma de ação interindividual orientada por uma finalidade específica; um processo de interlocução que se realiza nas práticas sociais nos diferentes grupos de uma sociedade, nos distintos momentos da sua história" (BRASIL, 2001, p. 23-24). O conceito lembra bastante as palavras de um dos integrantes do Círculo de Bakhtin, Valentin Volóchinov (1895-1936), filósofo russo cujas palavras agora evocamos:

Efetivamente, o enunciado se forma entre dois indivíduos socialmente organizados, e, na ausência de um interlocutor real, ele é ocupado, por assim dizer, pela imagem do representante médio daquele grupo social ao qual o falante pertence. A palavra é orientada para o interlocutor, ou seja, é orientada para quem é esse interlocutor [...] (VOLÓCHINOV, 2018, p. 204)

A realidade efetiva da linguagem não é o sistema abstrato de formas linguísticas nem o enunciado monológico isolado, tampouco o ato psicofisiológico de sua realização, mas o acontecimento social da interação discursiva que ocorre por meio de um ou de outros enunciados (VOLÓCHINOV, 2018, p. 218-219).

Relacionando o conceito apresentado pelos PCN e as reflexões do autor russo, vê-se notadamente o embasamento teórico que constrói o documento oficial de 1997. Ao assumir a linguagem como um ato, uma ação, uma prática social, os PCN alinham-se ao pensamento que vê a linguagem como um acontecimento essencial e fundamentalmente Revista X, v. 16, n. 3, p. 798-821, 2021. 
sociointerativo, isto é, constituída a partir de uma atividade interativa entre dois sujeitos situados historicamente. Isso traz de imediato, na nossa concepção, dois impactos consideráveis para como a escola passa a conceber e ensinar a língua materna.

Um primeiro impacto refere-se ao próprio objetivo de ensino de português, uma vez que ver a linguagem como um acontecimento social implica que as atividades de sala de aula, no ensino dessa disciplina, devam também estar constituídas no sentido de desenvolver uma série de competências e habilidades para o estudante não só compreender essa linguagem em seus diferentes usos, mas de fato usá-la. Desse impacto ocorre o outro: se a linguagem é interação, ou seja, é dialógica, incorporando uma função social real, um ensino de língua materna apenas baseado no domínio do código não contribui para o alcance da competência discursiva (BRASIL, 2001). Nesse sentido, uma nova concepção de linguagem exige novos objetivos para o ensino, que sejam e estejam afinados com a proposta geral do ensino de língua materna que os PCN buscam efetivar.

Assim, em relação aos objetivos de ensino de língua materna, os PCN são bastante claros: "espera-se que os alunos adquiram progressivamente uma competência em relação à linguagem que lhes possibilite resolver problemas da vida cotidiana, ter acesso aos bens culturais e alcançar a participação plena no mundo letrado" (BRASIL, 2001, p. 41). Seja através de práticas reais de escrita, de produção de textos orais ou práticas de leitura, os objetivos em defesa para o ensino de língua materna apresentados pelo documento visam em última instância à apropriação de diferentes linguagens para a plena participação social. Nesse sentido, os PCN se filiam à concepção de linguagem sociointeracionista, que tem no acontecimento real da língua a possibilidade de agir no contexto em que vive.

No plano da organização didática dos conteúdos da disciplina, os PCN, seguindo o pressuposto teórico da linguagem como instrumento de interação social, prevê um estudo da língua apoiado em dois grandes eixos: o uso da própria linguagem, levado a efeito a partir de práticas de leitura e produção de textos escritos ou orais; e a reflexão sobre a própria linguagem, em que se propõe a reflexão sobre os elementos da língua nos processos de sua utilização.

A grande diferença que os PCN prescrevem para o ensino de língua materna está no fato de que toda a prática de sala de aula deve estar centrada no uso da linguagem nas diversas manifestações sociais, incluindo aí a própria prática de reflexão sobre a língua, realizada a partir das necessidades dos estudantes quando do uso da linguagem. Essa acepção do projeto de ensino de língua diferenciava-se bastante do trabalho real ocorrido em sala de aula, no qual a gramática tradicional era vista como o programa de ensino, 
ao ensinar suas regras e fenômenos. A proposta aqui era substituir um ensino focado na gramática por um ensino focado nos reais usos.

Nessa perspectiva, as regras da gramática dão lugar ao texto, que passou a ser visto como o objeto de estudo central do ensino. Tal mudança buscou justificativa na própria máquina teórica que construía o documento: se o objetivo do ensino era a leitura, produção e análise de textos — considerados pelo documento a materialização da linguagem, dos diferentes discursos (BRASIL, 2001) - o aspecto teórico-metodológico das aulas deve partir do texto para o próprio texto, pois é através dele que usa e se manifesta a linguagem.

No que se refere aos conhecimentos gramaticais, o ponto em questão neste trabalho, estes, embora ainda importantes, saem do foco principal do ensino, não direcionando mais os conteúdos do ensino de língua portuguesa. $\mathrm{O}$ trabalho com a gramática normativa, segundo os PCN, ocorre no eixo da reflexão sobre a língua como uma forma de "trabalhar com o aluno o seu texto para que ele atinja seus objetivos junto aos leitores a que se destina" (GERALDI, 2004, p. 74). Em outras palavras, a gramática ganha uma função instrumental ao servir de conhecimento para a eficiência das práticas de uso da língua, a saber a leitura e a escrita. Nesse sentido, os PCN não abandonam o ensino de gramática, mas lhe dão uma nova função para auxiliar o estudante a desenvolver sua competência discursiva.

A respeito dos conhecimentos linguísticos dentro dos $\mathrm{PCN}$, o documento já traça novos conceitos e funções para eles a partir mesmo de sua designação, que passa a se denominar "análise e reflexão sobre a língua", apresentando um claro objetivo: "melhorar a capacidade de compreensão e expressão dos alunos, em situações de comunicação tanto escrita como oral" (BRASIL, 2001, p. 78). Vê-se aqui o caráter auxiliador de que se reveste essa prática de reflexão sobre a língua no intuito de aperfeiçoar as práticas de leitura e produção de textos. Nesse sentido, ensinar as regras da gramática é uma estratégia válida, desde que elas estejam contribuindo diretamente para ampliar as capacidades de uso da linguagem pelos estudantes.

O funcionamento da linguagem é, portanto, o foco sobre o qual se deve realizar o que o documento também chama, lembrando Geraldi (2004), de "análise linguística", isto é, práticas de análise dos aspectos linguísticos que contribuem para a ampliação das capacidades de comunicação dos alunos. Percebe-se que, de acordo com o documento, a análise linguística é uma atividade cognitiva de estudo e avaliação das possibilidades mais coerentes de compreender ou produzir os mais diferentes tipos de texto, respeitando seus sentidos e os adequando às intenções de seu produtor. 
Dentro dessa perspectiva, a prática de análise e reflexão sobre a língua, proposta pelos PCN, não abarca somente os aspectos gramaticais, mas também os aspectos discursivos e pragmáticos, uma vez que eles também contribuem, inclusive textualmente, para a produção dos sentidos, o que mostra relevância de seu estudo no interior das práticas de análise linguística.

\section{A BASE NACIONAL COMUM CURRICULAR E O ENSINO DE ANÁLISE LINGUÍSTICA}

Seguindo o mesmo conjunto de mudanças políticas e econômicas caracterizadas pela consolidação do neoliberalismo no Ocidente, acrescidos de uma ampliação cada vez maior dos engajamentos proporcionados por diferentes mobilizações sociais (CURY; REIS; ZANARDI, 2018), as lutas e discussões em torno de uma educação de qualidade começaram a ganhar uma visibilidade considerável, tornando-se mais latentes. Dentre as pautas, havia a defesa da educação como um direito fundamental do cidadão, o que exigia a elaboração de estratégias de forma a garantir tal direito a todas as pessoas. Essa demanda necessária, dentre outras ações, dá início a um longo - e em tese democrático — processo de construção de currículos para um balizamento das ações pedagógicas fora e dentro da escola.

Mesmo sob muitos questionamentos ${ }^{2}$, a segunda década deste século no Brasil foi marcada pela elaboração, pela primeira vez na história do país, de um documento referencial curricular para a educação básica como uma resposta a tais exigências. A Base Nacional Comum Curricular (BNCC, doravante), construída a partir da mobilização de diversos segmentos sociais, nasceu com a promessa de "balizar a qualidade da educação" e prezar pela "formação integral do cidadão" (BRASIL, 2018, p. 27) a partir do elenco de saberes e conhecimentos necessários ao pleno desenvolvimento do indivíduo no plano cognitivo, social, emocional etc.

Legalmente, a BNCC, enquanto discurso de lei - e, portanto, obrigatório objetiva "definir o conjunto orgânico e progressivo de aprendizagens essenciais que todos os alunos devem desenvolver ao longo das etapas e modalidades da Educação Básica, de modo a que tenham assegurados seus direitos de aprendizagem e desenvolvimento" (BRASIL, 2018, p. 7). A partir da defesa de uma educação de qualidade para todos,

\footnotetext{
${ }^{2}$ Cássio e Catelli Jr. (2019), através de seus convidados, apresentam um quadro bastante interessante a respeito dos impasses e questionamentos que a Base Nacional Comum Curricular traz para o ensino de alguns componentes curriculares que ela busca prescrever. Porém, por não serem nosso foco aqui, não trataremos detalhadamente desses aspectos.
}

Revista X, v. 16, n. 3, p. 798-821, 2021. 
esse ideal democrático é vislumbrado a partir da garantia de que, assegurando essas "aprendizagens essenciais", estar-se-á oportunizando, a todos os estudantes brasileiros, um "patamar comum de aprendizagem", cujos resultados implicam direta e principalmente na qualidade da educação. Em outras palavras, a BNCC tem como mote garantir educação de qualidade a todos.

Dentro desse viés, ganha destaque no documento o conceito de competência, vista como um conjunto de conhecimentos e habilidades mobilizados para resolver problemas da vida cotidiana. Como se pode observar neste primeiro ponto, o pressuposto básico da BNCC em criar situações de aprendizagem visando à plena participação social do aluno em sua comunidade é uma demanda que foi vista nos PCN e que a BNCC reforça, legitimando a atualização do material de 1997.

Dentro de uma discussão envolvendo o currículo, a BNCC, apesar de reiterar várias vezes que não se confunde com documento curricular, tem em sua própria constituição o caráter prescritivo que denota a sua atuação como currículo. E isso fica bastante claro quando tomamos o próprio conceito de competência e como ela é mobilizada no interior do texto, ao se relacionar um conjunto de competências e habilidades que os alunos deverão desenvolver ao longo de toda a educação básica. Embora esteja presente neste e nos PCN, é na BNCC que o significado de competência ganha materialidade, ganha ares de currículo com listas de conteúdos disciplinares a serem aprendidos pelos estudantes.

Em síntese, numa comparação entre PCN e BNCC, podemos dizer que, apesar das visíveis relações, esses dois documentos metodologicamente distinguem-se: enquanto os PCN são mais direcionados à apresentação, também de forma prescritiva, dos alicerces teórico-metodológicos que envolvem a prática educativa, a BNCC materializa uma espécie de prática ao prescrever os saberes e conhecimentos indispensáveis que todos os alunos devem aprender ao longo de toda a educação básica. Por outro lado, um é a consequência do outro, já que ambos, apoiados pelos mesmos princípios de democracia, de igualdade de direitos e oportunidades e de criticidade, traduz os interesses do outro e, de modo geral, traduz os interesses do Estado em uma possível manutenção de uma sociedade enraizada no capitalismo neoliberal, em que a educação serve como instrumento de formação de sujeitos profissionais, atuantes, competitivos e, decerto, prontos para desenvolver política e economicamente o país.

Sobre o ensino de língua materna, a BNCC explicita "dialogar com documentos e orientações curriculares produzidos nas últimas décadas, buscando atualizá-los em relação às pesquisas recentes na área e às transformações das práticas de linguagem" (BRASIL, 2018, p. 67). Nessa perspectiva, o texto conserva na sua essência a concepção 
de linguagem que defende ao destacar a visão "enunciativo-discursiva" a respeito dos fenômenos linguísticos. Tal concepção implica reconhecer na linguagem sua função social, da mesma forma como os PCN já preconizavam. Aliás, uma "novidade" que a BNCC traz ao atualizar sua concepção é o uso do termo "linguagem" no plural "linguagens" - como forma de englobar e destacar os textos não convencionais que passaram a se fazer presentes a partir do desenvolvimento daquilo que o documento chama de tecnologias digitais da informação e comunicação (TDIC).

A atualização proposta pela BNCC ao conceito de linguagem refere-se não só ao surgimento de outras formas semióticas, caracterizadas pelas TDIC, mas pela possibilidade de combinações entre essas diferentes linguagens. A questão, porém, é que o uso social que se faz dessa(s) linguagem(ns) permanece intacto na BNCC, preservando o mesmo ideal que se preconizava na década de 90. Em linhas gerais, essa preservação é textualizada no documento quando da explicitação do objetivo de ensino de língua materna:

Ao componente Língua Portuguesa cabe, então, proporcionar aos estudantes experiências que contribuam para a ampliação dos letramentos, de forma a possibilitar a participação significativa e crítica nas diversas práticas sociais permeadas/constituídas pela oralidade, pela escrita e por outras linguagens (BRASIL, 2018, p. 6768, ênfase nossa).

Como se pode observar, ao reconhecer o documento que as práticas de linguagem só se tornam significativas nas práticas sociais, podemos concluir que a definição de linguagem segue os postulados do Círculo de Bakhtin, para o qual a linguagem é troca, é intercâmbio social. Nesse sentido, não só as linguagens ditas convencionais - como a escrita e a oral —, como também os diferentes outros tipos de linguagem, podem ser mobilizados em função das intenções comunicativas de seus falantes em sua comunidade linguística.

Ao defender a linguagem como um processo, a BNCC destaca que a formação de sujeitos é histórica e socialmente construída, tornando-se, assim, coautores da sua própria prática formativa. Conforme se nota, a alteridade, à luz dos pensamentos do Círculo de Bakhtin, ganha eco nesse documento legal, visto que a construção de conhecimento deve se dar por meio de "ações intersubjetivas, geradas em atividades coletivas, pelas quais as ações dos sujeitos são reguladas por outros sujeitos" (BRASIL, 2017, p. 59).

Contudo, vale salientar que alguns estudiosos da área fazem algumas críticas acerca da implementação da BNCC no contexto educacional brasileiro. Nesse sentido, 
Azevedo e Damaceno (2017) alertam para: a) o grande desafio de uniformizar o ensino, sem desconsiderar as regionalidades, em mais de 190 mil escolas de Educação Básica espalhadas em diferentes regiões e mais de 2 milhões de professores em atividade; b) a noção de competência empregada de maneira limitada, com viés operacional, não colaborando com uma educação plural e diversa, mas que compactua com as competências encontradas nas matrizes de referência das avaliações nacionais; c) o não aprofundamento de noções importantes para a transposição didática (como gênero, texto, língua, discurso, escuta e leitura, produção textual e letramento); e e) a ausência de colaboração e produção de descritores de avaliação, visto que eles são construídos socialmente e trazem marcas ideológicas. Essas são algumas questões, entre outras, apontadas como falhas na BNCC que também se afastam dos pressupostos da Teoria Dialógica do Discurso, já que concebe um sujeito ativamente responsivo.

A inserção de outras linguagens nesse processo dá à disciplina de língua portuguesa uma nova configuração, de forma que o professor e de modo especial o aluno possam desfrutar de cada uso de cada linguagem como forma de ampliar seu repertório de participação social. É aqui que o documento se torna enfático, quando diz que "o importante, assim, é que o estudante se aproprie das especificidades de cada linguagem, sem perder a visão do todo no qual elas estão inseridas" (BRASIL, 2018, p. 63). E o documento continua: "é relevante que compreendam que as linguagens são dinâmicas, e que todos participam desse processo de constante transformação" (BRASIL, 2018, p. 63). Assim, o ensino de língua materna se torna um campo em que se cruzam diferentes linguagens, cujas práticas auxiliam no desenvolvimento de diversas competências.

$\mathrm{O}$ discurso da BNCC, ao se trabalhar a linguagem para desenvolver as competências, demonstra a grande iniciativa do documento em possibilitar, através das práticas pedagógicas, a inserção do indivíduo no mundo letrado, de modo que este possa participar das diferentes manifestações sociais em que se usa a linguagem. Para isso, ganha destaque no texto a prática da valorização das variedades linguísticas e da linguagem escrita como instrumento de interação, de participação social, de negociação de sentidos, valores e ideologias ou de fruição estética. Em outras palavras, o documento busca deixar claro que é a partir da linguagem que o indivíduo se insere no mundo, atuando e sendo transformado por ele.

Ganha ênfase também dentro das competências o desenvolvimento da aproximação do estudante com outras manifestações de linguagem, principalmente as digitais, como forma de conhecê-las e utilizá-las para construir sentidos diversos e ampliar as possibilidades do sujeito de se inserir na sociedade que o cerca. Diante de tais 
competências, principalmente se se realizar uma comparação com os objetivos dos PCN, veremos que, de fato, há uma relativa atualização dos propósitos para se ensinar a língua materna, embora se conservem na estrutura os princípios mais sólidos da disciplina, no que se refere à apropriação da linguagem como forma de inserção social. Nesse sentido, a BNCC atualiza e ao mesmo tempo consolida uma política de ensino de línguas voltada para o desenvolvimento de habilidades que possam garantir, de igual modo e de acordo com o documento, a plena participação dos sujeitos em práticas reais de uso da linguagem.

As considerações feitas até aqui nos permitem confirmar que o texto continua, na BNCC, sendo o centro das atividades de linguagem na escola, uma vez que deve ser constante na disciplina a prática de "relacionar textos a seus contextos de produção e o desenvolvimento de habilidades ao uso significativo da linguagem em atividades de leitura, escuta e produção de textos em várias mídias e semioses” (BRASIL, 2018, p. 67). Dito de outra maneira, o texto é o objeto de ensino principal, porque é a partir dele que os sujeitos interagem em diferentes situações sociais de uso da língua. Entretanto, sabemos que há muito o que caminhar quanto a trabalhar o texto de maneira contextualizada, autêntica, no contexto escolar brasileiro.

Assim, a BNCC mantém a figura central do texto nas práticas de leitura, produção oral e escrita e análise linguística que a escola deve desenvolver no ensino de língua portuguesa. São justamente no interior dessas práticas de linguagem que a BNCC ampara a sua organização para sua prática pedagógica. Segundo o documento, a partir da organização didática já apresentada em outras propostas curriculares - e aqui citamos os próprios PCN - o ensino de língua materna deve ser desenvolvido considerando as práticas de oralidade, leitura/escuta, produção (escrita e multissemiótica) e análise linguística/semiótica com o propósito de construir uma educação linguística para as práticas sociais. Nesse sentido, o texto, perpassando todos esses eixos, confirma a sua centralidade no ensino, definindo os conteúdos, as habilidades e os objetivos, sempre considerado a partir de um gênero discursivo que, segundo a BNCC, tem a sua circulação em diferentes campos/esferas sociais de uso da linguagem.

A preocupação principal da BNCC, no que se refere ao ensino de língua portuguesa, é propiciar ao estudante situações didáticas de uso e análise de diferentes fenômenos linguísticos incorporados às práticas de linguagem que estão sustentando a organização da disciplina. Para Suassuna (2014), o conjunto dessas práticas atende ao princípio básico, numa visão bakhtiniana, de relacionar a linguagem com a vida, o que permite, dentro dos movimentos de leitura, fala, escuta, escrita e análise dos mais diferentes textos, uma exploração dos modos como os textos dizem o que dizem, 
como se estruturam e emergem de seus contextos de produção, quem são seus (inter) locutores, quais são as relações entre sua arquitetura e seus conteúdos; que propósitos os guiam (SUASSUNA, 2014). Assim, a BNCC parece estar alinhada com o pensamento contemporâneo a respeito do ensino de língua a partir do desenvolvimento dessas práticas.

No plano do ensino dos conhecimentos gramaticais, a BNCC também retoma grande parte da discussão feita pelos PCN e os amplia, adicionado a este eixo os textos constituídos por outras semioses. Usando o termo "análise linguística/ semiótica", a BNCC segue as orientações adquiridas pela academia ao propor que o ensino dos conhecimentos linguísticos seja realizado não como um fim em si mesmo, mas desenvolvido "transversalmente aos dois eixos - leitura/escuta e produção oral, escrita e multissemiótica - e que envolve análise textual, gramatical, lexical, fonológica e das materialidades das outras semioses" (BRASIL, 2018, p. 80). Nesse sentido, o documento acompanha a discussão teórico-metodológica feita não somente por outros documentos curriculares anteriores, mas se alinha ao que, por exemplo, Mendonça (2006) e Geraldi (2004 [1984]) já discutiam a respeito do ensino de gramática numa perspectiva mais discursiva.

Instituindo como foco de trabalho na análise linguística/semiótica a prática reflexiva sobre os elementos linguísticos e semióticos que ocorrem simultaneamente às práticas de leitura/escuta e de produção de textos orais, escritos e multissemióticos, o referencial curricular, para Sousa (2019), oficializa dois aspectos muito importantes: a própria prática de análise dentro do estudo dos elementos gramaticais e a importância destinada ainda à norma-padrão. O primeiro aspecto, pontua o autor, está no fato de que a análise linguística/semiótica não tem a ver com as práticas tradicionais de classificação de termos descontextualizados, memorização de várias definições ou mesmo correção de frases seguindo a gramática normativa de cunho tradicional; em vez disso, é proposta uma atividade de reflexão sobre as práticas de leitura e produção de textos, como o próprio documento define:

O Eixo da Análise Linguística/Semiótica envolve os procedimentos e estratégias (meta)cognitivas de análise e avaliação consciente, durante os processos de leitura e de produção de textos (orais, escritos e multissemióticos), das materialidades dos textos, responsáveis por seus efeitos de sentido, seja no que se refere às formas de composição dos textos, determinadas pelos gêneros (orais, escritos e multissemióticos) e pela situação de produção, seja no que se refere aos estilos adotados nos textos, com forte impacto nos efeitos de sentido (BRASIL, 2018, p. 80). 
Ainda segundo Sousa (2019), a análise e a reflexão dessas materialidades dos textos significam que a "aula de gramática” deve ocorrer a serviço das práticas de leitura/ escuta ou da produção de textos, "cujo processo de análise permite a compreensão não só do funcionamento desses textos, como revela para o estudante que os elementos gramaticais devem ser utilizados com finalidades específicas, a depender dos contextos sociocomunicativos" (SOUSA, 2019, p. 44). É nessa perspectiva que o trabalho com os conhecimentos gramaticais (e multissemióticos no geral) assume a visão funcional e social da linguagem, uma vez que parte do texto para uma análise que, novamente, desemboca no texto.

A BNCC não exclui das práticas de ensino de língua o trabalho com a nomenclatura, com a norma, com as regras, uma vez que, como já bem defendia Possenti (1996), é função da escola ensinar a língua padrão, já que é ela a que o aluno ainda não domina. O texto do documento afirma, porém, que não é um ensino de gramática para que o aluno memorize ou use as nomenclaturas e regras para acertar questões ou que conheça a língua "correta", mas que as use de acordo com as suas necessidades durante outras práticas — as de leitura/escuta e as de produção textual.

O ensino de gramática/análise linguística no domínio da BNCC está calcado, pelo menos naquilo que o documento deixa prescrito, numa relação intrínseca entre os elementos linguísticos e as funções que eles exercem no interior dos diversos textos, ajudando seus leitores/expectadores/produtores em seus projetos de dizer. Nesse sentido, os elementos linguísticos, as regras da norma-padrão, a terminologia e a própria metodologia de trabalho com esses conteúdos são ressignificados a partir de um tratamento mais contextualizado do fenômeno linguístico. Tal postura, como se pode constatar, alinha o ensino dos conhecimentos gramaticais a uma perspectiva sociointeracionista, em que tanto os elementos da língua, como o seu próprio funcionamento estão a serviço das relações sociais humanas mediadas pela linguagem.

\section{CONSIDERAÇÕES FINAIS}

A discussão realizada em torno dos $\mathrm{PCN}$ e da $\mathrm{BNCC}$ a respeito do ensino de língua portuguesa e, em especial o ensino de gramática/análise linguística, permite concluir que tais textos, conforme os apontamentos de Machado (2002), prefiguram as ações do trabalhador, uma vez que "definem as tarefas de cada trabalhador, os objetivos, as condições materiais, o desenvolvimento temporal, os resultados que delas são esperados, pré-definindo as responsabilidades dos agentes envolvidos" (MACHADO, 2002 , p. 41). Nesse sentido, esses documentos prescrevem um tipo de trabalho que cabe Revista X, v. 16, n. 3, p. 798-821, 2021. 
ao professor o desenvolvimento de forma a atingir os interesses que transpassam esses textos. No caso dos PCN e, mais recentemente da BNCC, tais interesses refletem uma visão econômica e mercantil das situações didático-pedagógicas no intuito de preparar os jovens para o mundo neoliberal.

Conforme pontuam Machado e Bronckart (2005), "as prescrições são um elemento essencial para a apreensão das propriedades do trabalho educacional" (MACHADO; BRONCKART, 2005, p. 188). Portanto, se se quiser compreender melhor não só as práticas realizadas em ambiente de sala de aula (trabalho realizado), como também as práticas que devem ser desenvolvidas (trabalho prescrito), é muito importante conhecer e analisar os textos que buscam direcionar o trabalho docente na escola, já que eles influem na ação de ensinar, determinando a sua realização (MACHADO; BRONCKART, 2005).

Nesse processo, os PCN e a BNCC são documentos ricos de ações prescritas, uma vez que os dois documentos, por serem guiados por uma perspectiva sociointeracionista da linguagem, confluem muitas considerações a respeito do ensino dos conhecimentos gramaticais a partir de uma vertente que toma a língua em função de seus usos sociais. Tais concepções, seus objetivos, sua organização didática e — no caso específico da BNCC — seus próprios saberes a serem ensinados ao longo da educação escolar indicam que o ensino como trabalho permite uma configuração do ensino de português assentado numa visão interacionista de linguagem, cujas práticas didáticas devem contribuir para a ampliação dos letramentos dos estudantes (KLEIMAN, 1995, 2001; KLEIMAN, SIGNORINI, 2000).

\section{REFERÊNCIAS}

AMIGUES, R. Le travail enseignant: prescriptions et dimensions collectives de l'activité. Les Sciences de l'éducation - Pour l'Ére nouvelle, Paris, v. 42, n. 2, p. 11-26, 2009. Disponível em: https://www.cairn.info/revue-les-sciences-de-1-education-pour-1-erenouvelle-2009-2-page-11.htm. Acesso em: 2 jan. 2021.

AZEVEDO, I.; DAMACENO, T. Desafios do BNCC em torno do ensino de língua portuguesa na educação básica. Revista de Estudos de Cultura, n. 7, jan./abr. 2017. Disponível em: https://seer.ufs.br/index.php/revec/article/view/6557/5387. Acesso em: 13 mar. 2021.

BARIONI, M. O professor iniciante de FLE: desafios e possibilidades de seu trabalho. 2016. Dissertação (Mestrado em Letras, Língua e Literatura Francesa) — Programa de Pós-Graduação em Estudos Linguísticos, Literários e Tradutológicos em Francês. Faculdade de Filosofia, Letras e Ciências Humanas, Universidade de São Paulo, São Paulo, 2016. 
BRASIL. Base Nacional Comum Curricular. Brasília, DF: Ministério da Educação, 2018.

BRASIL. Parâmetros curriculares nacionais: língua portuguesa: $1^{\mathrm{a}}$ a $4^{\mathrm{a}}$ séries do ensino fundamental. 3. ed. Brasília, DF: Ministério da Educação, 2001.

BRASIL. Parâmetros curriculares nacionais: terceiro e quarto ciclos do ensino fundamental: introdução aos parâmetros curriculares nacionais. Brasília, DF: Ministério da Educação, 1998.

BRONCKART, J.-P. O agir nos discursos: das concepções teóricas às concepções dos trabalhadores. Trad. Anna Rachel Machado e Maria de Lourdes Meirelles Matencio. Campinas: Mercado de Letras, 2008.

BRONCKART, J.-P.; MACHADO, A.; MATENCIO, M; (Org.). Atividade de linguagem, discurso e desenvolvimento humano. Campinas: Mercado de Letras, 2006.

CÁSSIO, F.; CATELLI Jr., R. (Org.). Educação é a base? 23 educadores discutem a BNCC. São Paulo: Ação Educativa, 2019.

CLOT, Y. A função psicológica do trabalho. Trad. Adail Sobral. 2. ed. Petrópolis: Vozes, 2007.

CLOT, Y. L'aspiration au travail bien fait. Journal de l'ecole de Paris du management, Paris, v. 1, n. 99, p. 23-26, jan./fev. 2013. Disponível em: https://www.cairn.info/resume. php?ID_ARTICLE=JEPAM_099_0023\&contenu=article. Acesso em: 2 jan. 2020.

CURY, C.; REIS, M.; ZANARDI, T. Base Nacional Comum Curricular: dilemas e perspectivas. São Paulo: Cortez, 2018.

FERRAREZI JR., C. Pedagogia do silenciamento: a escola brasileira e o ensino de língua materna. São Paulo: Parábola, 2014.

GERALDI, J. O texto na sala de aula. São Paulo: Ática, 2004.

KLEIMAN, A. Letramento e formação do professor: quais as práticas e exigências no local de trabalho? In: KLEIMAN, A. (Org.). A formação do professor: perspectivas da Lingüística Aplicada. Campinas: Mercado de Letras, 2001. p. 39-68.

KLEIMAN, A. Modelos de letramento e as práticas de alfabetização na escola. In: KLEIMAN, A. (Org.). Os significados do letramento: uma nova perspectiva sobre a prática social da escrita. Campinas, SP: Mercado de Letras, 1995. p. 15-61.

KLEIMAN, A. O processo de aculturação pela escrita: ensino da forma ou aprendizagem Revista X, v. 16, n. 3, p. 798-821, 2021. 
da função? In: KLEIMAN, A.; SIGNORINI, I. (Org.). O ensino e a formação do professor: alfabetização de jovens e adultos. Porto Alegre: Artmed, 2000. p. 223-243.

MACHADO, A. Trabalho prescrito, planificado e realizado na formação de professores: primeiro olhar. Scripta, Belo Horizonte, v. 6, n. 11, p. 39-53, 2002. Disponível em: http:/periodicos.pucminas.br/index.php/scripta/article/view/12448/9763. Acesso em: 19 fev. 2021.

MACHADO, A.; BRONCKART, J.-P. De que modo os textos oficiais prescrevem o trabalho do professor: análise comparativa de documentos brasileiros e genebrinos. DELTA, São Paulo, v. 21, n. 2, 183-214, 2005. Disponível em: https://revistas.pucsp.br/ index.php/delta/article/download/37685/25511. Acesso em: 19 fev. 2021.

NUNES, C. Análise discursiva dos PCNs de língua portuguesa de $5^{a}$ a $8^{a}$ série: a relação documento e projeto de governo. 2007. Tese (Doutorado em Letras) - Faculdade de Filosofia, Letras e Ciências Humanas, Universidade de São Paulo, São Paulo, 2007.

POSSENTI, S. Por que (não) ensinar gramática na escola. São Paulo: Mercado das Letras, 1996.

ROJO, R. (Org.). A prática de linguagem em sala de aula: praticando os PCNs. Campinas: Mercado de Letras, 2000.

SANTOS, L. História das disciplinas escolares: perspectivas de análise. Teoria \& Educação, Porto Alegre, n. 2, p. 21-29, 1990.

SOUSA, F. Desafios atuais para o ensino de gramática: reflexões sobre as habilidades de análise linguística/semiótica na Base Nacional Comum Curricular. Língua Nostra, Vitória da Conquista, v. 6, n. 2, p. 35-57, ago./dez. 2019. Disponível em: https://www. linguanostra.net/ index.php/Linguanostra/article/view/130/135. Acesso em: 10 jan. 2021.

SUASSUNA, L. As práticas de linguagem como objeto de ensino-aprendizagem de língua portuguesa. In: LEAL, T.; SUASSUNA, L. (Org.). Ensino de língua portuguesa na educação básica: reflexões sobre o currículo. Belo Horizonte: Autêntica, 2014. p. 69-86.

SUASSUNA, L. O que são, por que e como se escreveram os Parâmetros Curriculares Nacionais de Língua Portuguesa: o professor como leitor de propostas oficiais de ensino. In: MARINHO, M.; RIBAS DA SILVA, C. (Org.). Leituras do professor. Campinas: Mercado de Letras, 1998. p. 175-184. 
TORQUATO, C. Documentos oficiais relativos ao ensino de língua portuguesa, interculturalidade e políticas de letramento. Signum: estudos linguísticos, Londrina, v. 1, n. 19, p. 426-458, jun. 2016. Disponível em: http://www.uel.br/revistas/uel/index.php/ signum/article/view/23199/19306. Acesso em: 1 jan. 2021.

VOLÓCHINOV, V. Marxismo e filosofia da linguagem: problemas fundamentais do método sociológico na ciência da linguagem. Tradução de Sheila Grillo e Ekaterina V. Américo. 2. ed. São Paulo: Editora 34, 2018.

Recebido em: 23 fev. 2021. Aceito em: 15 mar. 2021. 